\title{
La vacuna anti-rotavirus, incorporada al calendario de vacunación mexicano, redujo la mortalidad por diarrea en niños
}

Rotavirus vaccine included in the Mexican vaccination schedule, reduced mortality from childhood diarrhea

\section{Objetivos}

Evaluar el efecto de la vacunación contra el rotavirus en las muertes por diarrea en niños antes y después de la introducción de la vacuna en el calendario nacional de México.

Diseño

Estudio ecológico*

Población

Niños menores de cinco años.

\section{Intervención}

En 2006 comienza la vacunación en las zonas más pobres de México. En mayo de 2007, el Ministerio de Salud amplió el programa recomendando que todo niño mexicano, nacido después del $1^{\circ}$ de febrero de 2007 , reciba dos dosis de vacuna, a los dos y cuatro meses de edad.

\section{Medición de resultados principales}

Para estimar la cobertura de vacunación se utilizaron datos administrativos provenientes del Centro Nacional para la Salud de la Infancia y la Adolescencia (CENSIA). Se obtuvieron datos de muerte por diarrea entre enero de 2003 hasta mayo de 2009 en niños menores de cinco años. Se comparó la mortalidad por diarrea en 2008 y en los períodos estacionales de alta circulación de rotavirus durante los años 2008 y 2009, con la mortalidad por diarrea antes de la introducción de la vacuna (2003 a 2006).

\section{Resultados principales}

Se estima que la cobertura de vacunación en niños menores de 11 meses hasta diciembre de 2007 fue de $74 \%$ para la primera dosis y $51 \%$ para la segunda dosis. Los resultados principales se expresan en la tabla 1.

Tabla 1: Mortalidad por diarrea en niños menores de 59 meses en México en 2008 vs. 2003 a 2006, estratificado por grupos de edad*.

\begin{tabular}{|c|c|c|c|c|c|c|c|}
\hline \multirow[b]{2}{*}{ Grupos de edad } & \multicolumn{2}{|c|}{$N^{0}$ de muertes por diarrea } & \multicolumn{2}{|c|}{ Mortalidad por diarrea $/ 100.000$} & \multirow{2}{*}{$\begin{array}{c}\text { Reducción } \\
\text { relativa } \\
\text { (95\% IC) }\end{array}$} & \multirow[t]{2}{*}{ NNT } & \multirow[t]{2}{*}{ Pt } \\
\hline & 2003 a 2006 & 2008 & 2003 a 2006 & 2008 & & & \\
\hline 0 a 59 meses & 1.793 & 1.118 & 18,1 & 11,8 & $35 \%$ (29 a 39$)$ & 15.873 & $<0.001$ \\
\hline$\leq 11$ meses & 1.197 & 680 & 61,5 & 36,0 & $41 \%$ (36 a 47$)$ & 3.922 & $<0.001$ \\
\hline 12 a 23 meses & 421 & 285 & 21,1 & 15,0 & $29 \%$ (17 a 39$)$ & 16.393 & $<0.001$ \\
\hline 24 a 59 meses & 175 & 153 & 2,9 & 2,7 & $7 \%(-14$ a 26$)$ & - & 0.44 \\
\hline
\end{tabular}

*Los valores del período de referencia se calcularon como la suma de las medianas mensuales de muertes por diarrea durante 2003 a 2006.

\section{Conclusiones}

Luego de la introducción de la vacuna al calendario de vacunación, durante dos estaciones consecutivas de alta circulación

de rotavirus, se observó una disminución de las muertes por diarreas en los niños mexicanos.

Fuente de financiamiento: no reportada

\section{Comentario}

Otros estudios ya han demostrado la eficacia de la vacuna contra el rotavirus. Un estudio realizado en Sudáfrica y Malawi demostró que la vacuna redujo significativamente la enfermedad grave por rotavirus en un $61,2 \%$ de los niños durante el primer año de vida ${ }^{1}$.

En este trabajo, si bien la disminución de la mortalidad pudo haber estado relacionada con mejoras sanitarias ajenas a la vacunación (medidas de higiene, saneamiento ambiental, diagnóstico y tratamiento adecuados) la reducción en la mortalidad fue mayor en el grupo de niños menores de 12 meses, lo cual coincide con la alta cobertura de vacunación obtenida en este grupo.

En el grupo de 12 a 24 meses la muerte por diarrea se redujo casi un $30 \%$, aunque solo un 10 a $15 \%$ de esta población fue elegible para la vacunación. Este resultado indica que la vacunación de los bebés susceptibles también puede proteger a los niños no vacunados por efecto rebaño*. Este beneficio indirecto también ha sido evidenciado en un análisis reciente de enfermedades severas no fatales por rotavirus llevado a cabo en EE.UU., el cual demostró una disminución en la morbilidad que fue mayor de la esperada en base a las coberturas de vacunación?

Entre las limitaciones de este estudio mencionamos que no se pudo cuantificar la reducción de las muertes atribuibles a la vacunación ya que los datos de coberturas de vacunación resultaron insuficientes. Por otro lado, si bien no se pudo confirmar si las causas de muertes por diarrea fueron producto de la infección por rotavirus, la marcada estacionalidad de este virus y las muertes por diarrea ocurridas en invierno en México permiten evaluar indirectamente el efecto de la vacunación sobre las tasas de mortalidad.

\section{Conclusiones de los comentadores}

La infección por rotavirus ocurre por igual en países desarrollados y en vías de desarrollo. Es importante para disminuir la circulación de este virus combinar las medidas higiénicas de prevención con la inmunización. Esta vacuna debería introducirse de inmediato en las zonas de alta mortalidad y ser accesible a los niños que más la necesitan. La vigilancia continua de las muertes por diarrea y estudios epidemiológicos podrían resultar útiles para confirmar la asociación entre la disminución de eventos fatales por diarrea y la vacunación contra el rotavirus.

*Ver glosario

Ingrid Andrés, María José Bellomo, Lionel Simoncini, Luis Di Giuseppe [ Farmacéuticos del Plan de Salud. Hospital Italiano de Buenos Aires. luis.digiuseppe@ @ospitalitaliano.org.ar ]

Andrés I, Bellomo JM, Simoncini L, DiGiuseppe L. La vacuna anti-rotavirus, incorporada al calendario de vacunación mexicano, redujo la mortalidad por diarrea en niños. Evid Act Práct Ambul. Oct-Dic 2011;14(4):126. Richardson V, Hernandez-Pichardo J, Quintanar-Solares M, et al. Effect of rotavirus vaccination on death from childhood diarrhea in Mexico. N Engl J Med 2010;362(4):299-305. PMID: 20107215.

Referencias

1. Madhi S, et al. Effect of Human Rotavirus Vaccine on Severe Diarrhea in African Infants. N Engl J Med. 2010;362:289-298.

2. Tate J, y col. Decline and Change in Seasonality of US Rotavirus Activity After the Introduction of Rotavirus Vaccine. Pediatrics 2009;124:465-471.

126 EVIDENCIA - Actualización en la Práctica Ambulatoria - Octubre/Diciembre 2011 - Disponible en internet: www.evidencia.org 